\title{
On competence, curiosity and creativity
}

\author{
Geoff Norman
}

Published online: 18 October 2012

(C) Springer Science+Business Media Dordrecht 2012

A few days ago, I decided to take a lunch break and wandered over to the student centre to get a pizza slice. I sat down opposite a medical student who I had known when I taught him statistics as an undergraduate in our Bachelor of Health Sciences program. And like many of these students, he went on to medical school.

$\mathrm{He}$ is one of the new norms in Canadian medical schools. His parents are engineers; they escaped from Iraq with forged passports after the Gulf War. While he was born in Iraq, he came to Canada at a young age and so speaks and thinks like a typical intelligent 20 -something Canajun. And like the many sons and daughters of immigrants who now are strongly represented in our medical schools, he is very bright, articulate, and hard working; one of those students who makes the academic profession worthwhile.

$\mathrm{He}$ is now in first year at McMaster. He is experiencing the "COMPASS Curriculum" that Alan Neville and I designed about a decade ago (Neville and Norman 2010), whose centerpiece is encouraging students to actively apply basic science concepts to clinical cases. We see it as an evolution of Problem Based Learning; others may see it as just another variant. But we did try very hard to put some active excitement about learning back into the curriculum, and in doing so, found ourselves constantly referring back to the first MD curriculum (and the first PBL curriculum anywhere), which exemplified this link between science and practice. More on this later.

As the student and I talked, I was dismayed to find that he was bemoaning all the facts he had to memorize in medical school, and recalling with nostalgia the kind of educational experiences he had as an undergraduate (a year ago), where they were encouraged in "inquiry" classes to think through creative solutions of problems, not just find out answers.

My first reaction was dismay, that my lovely curriculum had been so subverted. But on further reflection, I began to realize that the issue is not just at the level of one curriculum. The practice of medicine, like any profession, does not really reward creativity, nor, from a utilitarian perspective, should it. A professional acquires the status by mastering a large and specialized body of knowledge-knowledge that other people created. His role is not

G. Norman $(\bowtie)$

McMaster University, Hamilton, ON, Canada

e-mail: norman@mcmaster.ca 
to add to this knowledge, but to use his judgment in applying this knowledge to his client's problem.

Of course a few medical graduates DO generate new knowledge as researchers, but this does not require any professional qualification, as my own career attests, since they do not have clients. So, while we may pay lip service to general traits like curiosity and creativity, we certainly do not operationalize these in courses or units. We don't reward curiosity; we reward competence. Nothing demonstrates this more clearly that the current movement toward a competency-based curriculum, where competence is judged entirely on the basis of mastery of defined skills.

Paradoxically, in graduate school, "competent" is almost a pejorative term, as in, "Well, he's competent enough but he's not very creative." Competence is the bottom rung of the ladder; the foundation of the house. And it's assumed that anyone who is not an abject failure is at least competent.

Competence, as expressed as mastery of a defined body of knowledge and skills was not always the "gold standard". Back when McMaster PBL was developed, the dominant mantra was that all knowledge would change every 5 years, so students had to acquire the skills to acquire new knowledge. And it then followed that they need not worry too much about acquiring today's knowledge. So examinations of knowledge were viewed with disdain, and "problem-solving skills" were the jewel in the PBL crown. Although the mantra was completely wrong, it was a liberating force. Curriculum committees were liberated from the tyranny of behavioural objectives and could encourage students to follow their interests, since it mattered less what you learned than how you learned.

One consequence was that the hidden curriculum at McMaster was really about applied physiology - we wanted students to marvel at how the body works just like the kid with a new chemistry set. Here are a few of the problems used in that curriculum:

1. Could the design or construction of the knee be improved?

2. Press the sharp end of a pint gently into your forefinger. Gradually increase the pressure until it hurts as much as you can bear. Observe and account for the skin changes.

3. National Geographic shows a vinyl cast of the blood vessels of a penguin. How can these birds stand barefoot on a cake of ice all their lives?

Sadly, the penguin problem would never find its way into today's curricula; after all our graduates won't have to treat penguins. But it was there not as a passing tip of the hat to vets, but because the circulation on the penguin's leg is analogous to counter-currents in the kidney.

Meanwhile back at the student centre, the conversation then drifted to what specialty he would go into. On the one hand, he was desperate to rediscover the kind of intellectual rewards he found as an undergraduate; on the other, he recognized that the greatest professional rewards in terms of autonomy and income were in procedure-driven specialties like ophthalmology, urology, and interventional cardiology. The more he went down the list of possibilities, the more it became evident that he was faced with a Faustian choice between intrinsic and external rewards. But as I engaged in this search with him, I was struck by how little he understood about what doctoring was all about. To this point, his entire life was focused on getting INTO medical school, and very little time was devoted to thinking what it would be like to get OUT OF medical school and become a doctor.

I read somewhere that current statistics are that about $30 \%$ of undergraduates want to get into medical school, but only $3 \%$ will. As anyone involved in undergraduate (premed) 
education will attest, this statistic is an indicator of a massive distortion of the undergraduate experience. Students no longer take courses based on interest; they take "bird" courses where high marks are handed out like candies. Mark inflation is rampant; professors are challenged by deans because their grades aren't high enough (yes, I can name names!). When a student receives a mark lower then her expectation, it is viewed as a mutual problem of the student and the professor (and often, her family).

All of these are now constant aggravations that degrade the undergraduate experience for students and faculty alike. And it makes the job of the admissions committee that much harder as grades inflate and students become better and better at gaming the system. Just about every admissions tool has one or more websites purporting to show students how to succeed.

But this is not the real tragedy. What has really been lost is the opportunity for students to pursue an alternative career that interests and enchants them; that permits them to exercise creativity and curiosity. It may not be an easy career path, it may not pay as well or offer the same security, but for many it may be far more rewarding.

I cannot offer solutions. But perhaps by identifying the real "hidden curriculum", which extends much further back than Day 1 of medical school to undergraduate, high school or earlier, we can devise strategies to return some sanity (and some reward) to the medical school experience.

The first education dean at McMaster, Bill Walsh, once said about PBL that "All we really want is for them to become doctors and have some fun doing it". They achieved that in the sixties, but current social forces make it harder and harder. It is, however, something to strive for.

\section{Reference}

Neville, A. J., \& Norman, G. R. (2010). Michael G. DeGroote School of Medicine Faculty of Health Sciences, McMaster University. Academic Medicine, 85, S624-S627. 